\title{
Latent Class Analysis of Students' Science Motivation: A Comparison Between the United States and China
}

\author{
Wenjuan Sang (Corresponding author) \\ School of Education, Indiana University \\ 107 S Indiana Ave, Bloomington, Indiana 47405, United States \\ Tel: 1-812-606-2432Ｅ-mail: wsang@iu.edu \\ Adam Maltese \\ School of Education, Indiana University \\ 107 S Indiana Ave, Bloomington, Indiana 47405, United States \\ Tel: 1-812-856-8059Ｅ-mail: amaltese@indiana.edu
}

Received: May 14, 2020 Accepted: November 10, 2020 Published: November 27, 2020

doi: 10.5296/ire.v8i2.17030 URL: https://doi.org/10.5296/ire.v8i2.17030

\begin{abstract}
Using latent class analysis (LCA), we examine the potential ways of classifying students' science motivation in the United States and China using data from PISA 2015. Based on a set of nine observed variables of science motivation, we identify three subgroups of cases varied in their internal patterns of motivation, covering, respectively, $24.78 \%, 12.85 \%$, and $62.37 \%$ of the entire sample size. Instead of classifying students into groups with a linear increase in motivation scores, latent class analysis shows that there are students who feel pure enjoyment in learning science but do not associate science with their future careers (Class 1), students who do not like learning science but believe science is important to their future (Class 2), and students who have both high enjoyment and the prospect of doing science for a living in the future (Class 3). Multinomial logistic regression reveals that science motivation groups are significantly affected by gender, nationality, and family background.
\end{abstract}

Keywords: Science motivation, Science education, Latent class analysis, Multinomial logistic model 


\section{Introduction}

In recent decades, science-, technology-, engineering-, and math-related fields (STEM) have had increasing influence on the economies of many countries (Freeman et al., 2014) and have also received greater attention from researchers. For secondary science education, researchers acknowledge the importance of understanding what prompts students to learn within STEM-related fields and ways to keep them in these fields from early ages through career entry (Perna et al., 2009), because they believe that high school math and science course choices and experience can affect students' pursuit of science in higher education (Crisp et al., 2009; Maltese \& Tai, 2011; Simpkins et al., 2006). The theories of motivation and science motivation, therefore, provide a valuable way of thinking and researching the reasons and influential factors behind students initiating and maintaining their behaviors toward science learning.

Although motivation theory has largely been used in psychology and education, many definitions are considered vague and insufficient to capture the whole picture of motivation (Kleinginna \& Kleinginna, 1981). To simplify, the concept here is generally defined as an “internal state that arouses, directs, and sustains" students' behavior (Glynn et al., 2011). Specifically, in the research field of STEM education, individuals believe that having the motivation to learn science can not only benefit students who long to become scientists in the future, but all young students, by improving their general science literacy, which enables them to understand scientific knowledge, raise scientific questions, arrive at logical conclusions, and grasp the impact that humans have made on the natural world (Bryan et al., 2011). To better understand science motivation, scholars have conducted varied studies with instruments for measuring students' motivation, especially in learning science (Glynn \& Koballa, 2006; Kempa \& Diaz, 1990).

This research is a part of the Assessing Multinational Interest in STEM (AMISTEM) project, a cross-national research study that has collected and analyzed data in the United States, China, and Australia. Using self-designed survey questionnaires, focus groups, and interviews, this international comparative study explores students' interest and experiences in STEM. This study aims to examine data from the United States and China to uncover mutually exclusive motivation factors in learning science and the demographic indicators that influence the probability that students will fit into one motivation group versus another.

\section{Literature Review}

This research focuses on three bodies of scholarly research: 1) the mechanics of learning motivation, specifically about students' science learning in a school context; 2) the possibility of splitting students into groups based on their quantitative motivation scores or qualitative evaluations given by teachers; and 3) the predictive power of students' background on their different motivation levels. As mentioned above, quantitative instruments that measure motivation, in general, have been developed and examined since the 1900s. Kempa and Diaz validated Adar's four motivational traits model, in which students' motivation is attributed to their needs to "achieve," to "satisfy their curiosity," to "discharge a duty" and to "affiliate with people" (Kempa \& Diaz, 1990). The questionnaires designed by Tuan and Bryan's 
teams both borrow the cognitive part of this model (Bryan et al., 2011; Tuan et al., 2005). In the former, Students' Motivation toward Science Learning (SMTSL), students' science motivation is measured using six scales: self-efficacy, active learning strategies, science learning value, performance goal, achievement goal, and learning environment stimulation (Tuan et al., 2005). In the latter, science motivation is defined using three sub-categories: intrinsic motivation, self-efficacy, and self-determination (Bryan et al., 2011), which cover both internal and external influential factors. This questionnaire keeps the category of "self-efficacy" to highlight students' perception of their ability to accomplish science learning and experience corresponding achievement. It uses "self-determination" to evaluate how intensively students try to finish their duty to learn science and the strategies they use. Finally, the intrinsic motivation scale asks students to recall whether learning science is an end itself, instead of a means for them. Both questionnaires have been tested on junior high students in Taiwan and in the United States, respectively, to confirm their validity and reliability.

Extant analyses of motivation usually treat the scales collected from science motivation questionnaires as the dependent variables in their models to explore which factors can influence students' science motivation. This approach is limited, since researchers are unaware if a significant division among a group of people exists based on their science motivation levels. Glynn and his colleagues grouped college students from non-science majors into four groups by dividing the full point of the SMQ (150) by equal intervals: low (scored 30-59), moderate (scored 60-89), high (scored 90-119) and very high (scored 120 and above). They revised this approach later using a simplified two-class model (Glynn et al., 2007). From a homological point of view, students' science motivation can be roughly split into two groups: the high motivation group and the low motivation group (Glynn et al., 2009). Students are labeled "high motivation" and "low motivation" based on their scores on each factor of the SMQ. For instance, in the five-item ordered scale for self-efficacy, students who marked more items as "Often" and "Always" were labeled with "high motivation." Conversely, students who responded "Never" and "Rarely" to more items were defined as having "low motivation" on the self-efficacy scale. This study developed the classification further by adding the "Moderate" class after another test on students in secondary education (Bryan et al., 2011). The three-group model is generated by students' responses to the same science motivation questionnaire and the study quotes their interviews to support this model. However, the authors present neither the criteria nor the statistical method of conducting the classification. The three-class division is applied in Tuan et al in a different way (Tuan * et al., 2005). Instead of generating groups using self-reported data, they asked teachers to classify their students into "Low," "Moderate," and "High" groups. The classification was used as an independent variable to test whether students in different groups have significant differences on the factors of the SMTSL questionnaire. Although this type of classifications helps us understand science motivation for different groups of individuals, these techniques suffer from insufficient statistical reliability, which makes it more difficult to build upon this data in future research.

There are multiple methods to quantify motivation and students' science motivation in the American context that provide insights into identifying indicators of motivation level and 
explaining their statistical power. Gender differences have long been discussed. Some high-school level studies show that girls have significantly lower scores on science attitude measurements than boys (Weinburgh, 1995), more tend to drop out from science classes (Catsambis, 1995), and they are less apt to pursue science-related majors or careers (Steele, 1997). However, some research does not support the effect of gender on students' science motivation (Stake, 2006). Other research suggests that females' disadvantaged situation in learning science stems from more complicated factors, such as the stereotype that science is masculine (Debacker \& Nelson, 2000).

Another equivocal factor is family influence. Although research demonstrates that parents' education and encouragement for their children are important indicators for children's long-term aspiration and motivation, their effects are intertwined with other factors, such as students' ability and school environments (Baker \& Leary, 2003; Rayman \& Brett, 1995; Stake, 2006). In the American context, race is another important factor. For instance, Britner and Pajares found that white middle school students have higher self-efficacy and achievement in middle school science while African American students have stronger task goals (Britner \& Pajares, 2001).

Although prior studies on students' motivation in learning science have provided rich results for American students, the amount of research on Chinese students' science motivation levels, especially using them as comparative counterparts to American students, is limited. By addressing topics such as cultural traditions, teacher- and exam-centered teaching, textbook and curriculum adoption, and parental involvement in after-school activities, previous research has drawn attention to science education as a system in China (Gao, 1998; Lewin, 1987; Wang et al., 1996). Among those studies, teaching methods and teaching philosophies in China are far more strongly emphasized than the mechanics of learning. Qualitative studies of learning motivations among Chinese college students suggest that Chinese students may be highly motivated by external motivation, such as a duty to the country or their parents. Thus, they value their learning, because it will fulfill their life goals and also contribute to the collective good. They appreciate hard work and tend to have a realistic evaluation toward their tasks and achievement (Chen et al., 1996). Those findings share some overlapping components with the science motivation model and lead to the question as to whether the impact of a student's nationality can be examined via quantitative research.

\section{Hypotheses}

Based on our review of the literature, we propose three major hypotheses:

H1. Students' science motivation levels can be divided into two or more groups. Members in one group share the same patterns of motivation with each other and have significant differences from individuals in other groups.

H2. Within the demographic variables, gender and family background influence an individual student's group classification.

H3. Nationality can differentiate students' motivation levels, keeping other factors constant. 
In the following sections, we examine all three hypotheses using empirical data.

\section{Methods}

This research uses quantitative data analysis throughout. Since our goal is to examine potential ways to group secondary students based on their science motivation scores, we first propose latent class analysis (LCA) to group students into mutually exclusive classes. With the classes generated through LCA analysis, we use multinomial modeling (MNLM) to examine important predictors that impact each individual student's grouping results.

\subsection{Measurement and Descriptive Analysis}

We used the Programme for International Student Assessment (PISA) 2015 student individual data for this analysis, which was downloaded from the OECD website (http://www.oecd.org/pisa/data/2015database/). PISA assesses mathematics, science, and reading literacy among 15-year-old students. It includes datasets of individual students, parents, and schools from more than 60 different countries. Compared to previous PISA installments, PISA 2015 collected data from four regions of China, namely Beijing, Shanghai, Jiangsu, and Guangdong, making it a better representative of Chinese students' learning conditions and outcomes. The final number of observations we obtained after cleaning the data was $\mathrm{N}=18,827$ for students from both the United States (48.07\%) and China $(51.93 \%)$. Slightly more than half of the data comes from youth who identified as male $(51.26 \%)$, meaning the sample data also keeps a balance in gender representation. By using the variable to describe whether students speak foreign languages at home, we took into account that students may be disadvantaged by not belonging to the majority culture in one society. Across the entire sample, $75.27 \%$ of the sampled students used the same language as the PISA test at home, while $24.73 \%$ used foreign languages.

We also estimated the influence of family background by controlling for several household asset standardized indices provided by PISA. In the PISA 2015, the household possession measurement was derived from the availability of 16 household items at home as reported by students. In this research, we used three out of the five indices generated by mutually exclusive items. The WEALTH variable captures household material possessions, such as a dishwasher, the students having their own room, a connection to the internet, etc. The CULTPOS variable describes family cultural possessions, which most notably refer to books and artifacts owned by a family. The HEDRES variable presents whether a family provides a study space, equipment, and learning materials to students. To measure family economic, social and cultural status, a widely used scaled variable in the PISA is ESCS, which compiles both family household possessions, parents' occupation, and parents' highest education levels. To avoid multicollinearity in the regression models, we used only parental education (PARED). The mean parents' educational years across the country is 12.88 , meaning that on average, the students' parents had obtained a high school-level or equivalent education in both the United States and China. 
Table 1. Descriptive statistics of predictors by country

\begin{tabular}{lllll}
\hline & \multicolumn{2}{l}{ United States } & \multicolumn{2}{c}{ China } \\
Variable & Mean & SD & Mean & SD \\
\hline Gender (Female=1) & 0.50 & 0.41 & 0.47 & 0.69 \\
Foreign Language (Speaking foreign language=1) & 0.22 & 0.34 & 0.02 & 0.18 \\
Parents' Highest Education & 13.61 & 2.29 & 10.90 & 4.72 \\
Family Wealth & 0.50 & 0.88 & -1.27 & 1.50 \\
Family Cultural Possession & -0.08 & 0.80 & 0.08 & 1.10 \\
Family Educational Possession & -0.10 & 0.93 & -0.46 & 1.60 \\
\hline
\end{tabular}

\subsection{Science Motivation Indicators on the PISA}

Nine indicators for science motivation were used in the LCA. It is necessary to clarify that the term "science" here does not merely mean science as a single course, but also all science-relevant courses. They cover students' intrinsic and instrumental motivation in learning science. The original scale in the PISA 2015 items is a four-level Likert scale ranging from "Strongly disagree" to "Strongly agree" to measure students' self-reported experience about how they are motivated while learning science. The nine questions are varied, covering whether the respondent has fun learning science, makes an effort in learning science, and believes science will help him or her enter a career. This scale was modified by collapsing the original four-level scale into two levels to better fit the LCA requirements: "Strongly disagree" and "Disagree" were recoded as "Disagree," (0) and "Strongly agree" and "Agree" were recoded as "Agree" (1). Table 2 presents all nine indicators and the percentage of PISA 2015 respondents who gave a positive response to each of them. All values total more than $50 \%$, indicating that the respondents have an overall positive toward science learning. This result shows that American and Chinese students' science motivation is generally above the moderate level.

Compared to other methods of grouping students used in previous research, LCA tries to find latent variables that can explain both the observed (manifest) relationships among variables, taking into account the unobserved relationship they have with latent variables (Goodman, 2002; McCutcheon, 1987). Instead of analyzing discrete individuals, latent analysis centers itself on the relations among individual observations with the aim of sorting individuals into groups within which members resemble each other and are distinct from those in other groups (Marsh et al., 2013). In other words, it starts from the assumption that dichotomous survey responses to those nine variables will reveal associations to some degree. We used Mplus (B. Muthén, 1979; B. Muthén \& Christoffersson, 1981; B. Muthén \& Muthén, 2000; B. O. Muthén, 1989) to perform LCA to categorize the students into different classes based on their conditional motivation levels in science. LCA model solutions were compared based on the Bayesian information criterion (BIC) and entropy values (B. Muthén \& Muthén, 2000). A 
lower BIC value suggests a better-fitting model compared to higher BIC values. Entropy values represent the precision of assigning latent class membership, and a higher value indicates greater classification precision than a lower value (Klonsky \& Olino, 2008).

In LCA, the number of classes is pre-determined. Therefore, our goal here is to choose a correct number of latent classes $(K)$ that can best explain the association among the manifest variables. Usually, researchers explore different solutions with various numbers of groups until they find one that makes the most sense to both the theory and the nature of the data. It is useful to start testing the fitness of one independent model by placing all observations into one single latent class $(K=1)$. On the supposition that the single-class model does not fit the data very well, a two-class model $(K=2)$ is examined next. This operation proceeds until results indicate a clear class delineation (Celeux \& Soromenho, 1996). The assignment of respondents is based on their posterior membership probabilities calculated by Mplus. For instance, in a two-class model, if a respondent obtains membership probabilities of 0.7 in Class 1 and 0.3 in Class 2, this person is assigned to Class 1.

These latent classes serve as the dependent variable for a multinomial logistic regression model (MNLM) to assess the predictors for latent profile membership. In other words, instead of directly analyzing the responses to those nine manifest variables, we modeled the groups of respondents' science motivations that the LCA identifies to see how demographic variables influence the categories into which students fall. This modeling extends the standard binary logistic regression to predict outcomes with more than two categories. We performed MNLM using Stata 15 (StataCorp, 2017).

\section{Results}

Table 2 presents the proportion of sample respondents for each science motivation item split by the participants' nationality. After transferring to binary variables, the science motivation indicators tended to have means bigger than 0.5, meaning that the majority of the sample respondents provided positive feedback about their science motivation. Although it is not manifested in all items, students scored very high in some cases. With the item "I am making an effort in learning," for instance, the mean values of students from both countries are as high as 0.8 and 0.9 , respectively. It indicates that both American and Chinese students believe that they dedicate themselves when learning science. Compared to American students, their Chinese counterparts have higher agreement with these motivation-related items.

Table 2. Responses on each item of science motivation, split by nationality (mean and standard deviation; $0=$ Disagree, $1=$ Agree)

\begin{tabular}{llllll}
\hline & \multicolumn{3}{c}{ United States } & \multicolumn{2}{c}{ China } \\
\cline { 2 - 5 } Indicator & Mean & SD & Mean & SD \\
\hline I have fun when I am learning science & 0.72 & 0.37 & 0.81 & 0.55 \\
I like to read about science & 0.56 & 0.40 & 0.79 & 0.57 \\
\hline
\end{tabular}


I am happy working on scientific topics

$\begin{array}{llll}0.69 & 0.38 & 0.70 & 0.64 \\ 0.75 & 0.35 & 0.81 & 0.55 \\ 0.72 & 0.36 & 0.77 & 0.59\end{array}$

I am interested in learning about science

Making an effort in my school science subject(s) is worth it because this will help me in the work I want to do later on

What I learn in my school science subject(s) is important for me because I need this for what I want to do later on

Studying my school science subject(s) is worthwhile for me because what I learn will improve my career prospects

Many things I learn in my school science subject(s) will help me to get a job

$\begin{array}{llll}0.70 & 0.37 & 0.81 & 0.54\end{array}$

In order to identify clusters of observations that exhibit similar patterns in science motivation, we analyzed the responses of all nine manifest variables using LCA. Based on our literature review, we expect a division among motivation levels, such as the homological division of "high motivation" and "low motivation," according to which a student's attitude and activity in science learning are either driven by their interest or passion, or impeded by their reluctance or incompetence.

The results presented in Table 3 reveal several important insights. Here we compared the model fit likelihood ratio chi-square statistics $L^{2}$, using it to indicate the amount of unexplained relations in science motivation to determine the optimal number of classes, as suggested by Dunn and her colleagues (Dunn et al., 2006). First of all, the traditional two-class division of motivation level is not the best fit for our data, despite its supremacy compared to the one-class model. The result rejects the simple homological division that students' science motivation can be partitioned into merely two categories. Second, the three-class model reduces the $L^{2}$ by $28.97 \%$, which is $7.04 \%$ greater than the $L^{2}$ reduction inherent in a two-class solution. By passing the 5\% cutoff, it indicates that the three-group model is better than the two-group model (Alderson et al., 2007). In addition, the three-class model reduces the Bayesian Information Criterion (BIC) by 12816.743, showing very strong evidence for choosing the three-class solution over the two-class solution (Kass \& Raftery, 1995). Although the four-class solution reduces the BIC by 6757.789 , which is much larger than the criterion of 10 , it reduces $L^{2}$ by only $3.75 \%$ over the three-class model. As we conduct likelihood ratio tests to compare each estimated model to the model with one less class than it, we find that each model is significantly better than the one with a single class $(p<.001)$. 
Table 3. Latent class models fitted to the PISA 2015 science motivation items

\begin{tabular}{lllllll}
\hline Models & BIC & L2 & Entropy & No. Parm & p-value & $\begin{array}{l}\% \text { Reduction of } \\
\text { L2 }\end{array}$ \\
\hline 1. Class & 182106.950 & 91009.181 & -- & 9 & 0.000 & -- \\
2. Class & 142285.260 & 71049.121 & 0.917 & 19 & 0.000 & 21.93 \\
3. Class & 129570.353 & 64642.452 & 0.924 & 29 & 0.000 & 28.97 \\
4. Class & 122853.704 & 61234.913 & 0.919 & 39 & 0.000 & 32.72 \\
\hline
\end{tabular}

Entropy measures to what extent a mixture model can provide well-separated clusters (Celeux \& Soromenho, 1996). It ranges from 0 to 1.0 and the closer the value is to 1.0, the greater the precision in assigning latent class membership is (Klonsky \& Olino, 2008). Consistent with the $L^{2}$ and BIC comparisons above, the entropy value of the three-class solution is higher than the two-class solution and the four-class solution, suggesting that it is more precise to assign individual cases into three classes. Therefore, the three-class model will be the final latent class model we use for further analysis.

Table 4 shows the mean value of each item classified in tree clusters and the labels for each item in those classes. By ruling out the possible low/high split in motivation patterns, the result shows that the students' motivation level is not polarized, although the percentage of students falling into Class 2 is lower than the other two. A simple division may either underestimate or overstate a respondent's motivation if one does not express obvious pessimism or optimism in those items. In the first column of Table 4, we find that the Class 1 represents $24.78 \%$ of respondents. This group is different from the others by exhibiting the lowest passion and enjoyment toward learning science, but an intermediate level of belief about science learning's usefulness in their future work and careers. The second column displays that $12.85 \%$ of respondents belong to Class 2 , constituted by those who reported positive feelings while learning and reading things related to science. However, this group has the lowest mean scores for items related to the importance or worth of learning science to their future careers. People in this class constitute the smallest group in our model. The third class, listed in the right-hand column, represents $62.37 \%$ of respondents. Different from the members in the other two classes, respondents in this group are characterized by self-driven learning due to interest, self-confidence and belief in positive prospects for their future. They obtain pleasure and promote self-development in learning science. They believe that science fits closely with their interests and believe a tight connection exists between science courses and their future endeavors. This is consistent with the observation above in Table 2 that all items have means larger than 0.5 . 
Table 4. Relative size of latent profile classes and mean and standard error of motivation score for each item.

\begin{tabular}{|c|c|c|c|c|c|c|}
\hline \multirow[b]{2}{*}{ Class size $(\%)$} & \multicolumn{2}{|c|}{ Class 1} & \multicolumn{2}{|c|}{ Class 2} & \multicolumn{2}{|c|}{ Class 3} \\
\hline & 24.78 & & 12.85 & & 62.37 & \\
\hline Itemized mean and standard error & Mean & S.E. & Mean & S.E. & Mean & S.E. \\
\hline I have fun when I am learning science & 0.20 & 0.01 & 0.88 & 0.01 & 0.96 & 0.00 \\
\hline I like to read about science & 0.09 & 0.00 & 0.72 & 0.01 & 0.85 & 0.01 \\
\hline I am happy working on scientific topics & 0.09 & 0.01 & 0.88 & 0.01 & 0.93 & 0.00 \\
\hline $\begin{array}{l}\text { I enjoy acquiring new knowledge in } \\
\text { science }\end{array}$ & 0.22 & 0.01 & 0.96 & 0.00 & 0.98 & 0.00 \\
\hline I am interested in learning about science & 0.16 & 0.01 & 0.91 & 0.01 & 0.96 & 0.00 \\
\hline $\begin{array}{l}\text { Making an effort in my school science } \\
\text { subject(s) is worth it because this will } \\
\text { help me in the work I want to do later on }\end{array}$ & 0.71 & 0.01 & 0.39 & 0.01 & 0.99 & 0.00 \\
\hline $\begin{array}{l}\text { What I learn in my school science } \\
\text { subject(s) is important for me because I } \\
\text { need this for what I want to do later on }\end{array}$ & 0.61 & 0.01 & 0.15 & 0.01 & 0.97 & 0.00 \\
\hline $\begin{array}{l}\text { Studying my school science subject(s) is } \\
\text { worthwhile for me because what I learn } \\
\text { will improve my career prospects }\end{array}$ & 0.61 & 0.01 & 0.23 & 0.01 & 0.98 & 0.00 \\
\hline $\begin{array}{l}\text { Many things I learn in my school } \\
\text { science subject(s) will help me to get a } \\
\text { job }\end{array}$ & 0.58 & 0.01 & 0.16 & 0.01 & 0.93 & 0.00 \\
\hline
\end{tabular}

Table 5 provides the overview of the multinomial logistic regression. As hypothesized, the nationality variable differentiates the respondents into three groups. The Chinese sample (Chinese $=0$ ) serves as the baseline. That is, compared to Chinese students, students from the U.S. are more likely to be in Class 2, rather than Class 1 . The multinomial logit for American students relative to Chinese students is 0.35 units higher for being in Class 2 relative to Class 1 with all other variables in the model held constant. In terms of the odds ratio (i.e., opposite to the likelihood of being in Class 1), American students have 1.42 times the odds of being in Class 2 than their Chinese counterparts $(p<0.05$, two-tailed). Also, relative to Chinese students, the multinomial logit for American students is 0.46 units lower for being in Class 3 relative to Class 1. Chinese students have 1.58 times greater odds of being in Class 3 than their American counterparts ( $p<0.05$, two-tailed). Finally, relative to Chinese students, the multinomial logit for American students is 0.81 unit lower for being in Class 3 relative to Class 2 when all other variables in the model are held constant. Chinese students have 2.25 times the odds of being in Class 3 than their American counterparts ( $p<0.05$, two-tailed). 
The results demonstrate that gender also plays an important role. By exponentiating the coefficients, it is clear that the relative odds of being in Class 2 rather than being in Class 1 are $61.26 \%$ lower for females than for males with the same nationality and family background ( $p<0.05$, two-tailed). Also, the relative odds of being in Class 3 rather than Class 1 are $71.89 \%$ lower for females than for males with the same nationality and family background ( $p<0.05$, two-tailed). Gender also appears to be significant in comparing the relative odds between Class 3 and Class 2. Our result shows that female students are $17.35 \%$ more likely to be in Class 2 than Class 3 compared to male students.

Among all family background variables, family cultural possessions and family educational resources were shown to differentiate students' latent groups. Relative to being in Class 1, students with more family cultural possessions are more likely to be in Class 2 and in Class 3 . The former has a relative odds ratio of 1.32, implying that the odds of being in Class 2 rather than in Class 1 for students with more family cultural possessions are 1.32 times higher than for students with fewer family cultural possessions. The relative odds of being in Class 3 rather than Class 2 are not significant, meaning that family cultural possessions cannot effectively differentiate students in Class 3 and Class 2. Students whose families possess more educational resources are more likely to be in Class 3, relative to Class 1 and Class 2 . The relative odds of being in Class 3 rather than being in Class 1, for example, are $20.93 \%$ higher for students whose families have more educational resources than for students from families with fewer cultural possessions. Speaking foreign languages at home, parents' highest educational attainment, and family wealth, however, are not significant predictors in differentiating students' science motivation latent classes.

Table 5. Multinomial logistic model estimating the effects of predictors on latent class membership

\begin{tabular}{|c|c|c|c|c|c|c|}
\hline & \multicolumn{2}{|c|}{ Class 2 vs. Class 1} & \multicolumn{2}{|c|}{ Class 3 vs. Class 1} & \multicolumn{2}{|c|}{ Class 3 vs. Class 2} \\
\hline & Coef. & S.E. & Coef. & S.E. & Coef. & S.E. \\
\hline Nationality (the U.S.=1) & $0.35 * *$ & 0.11 & $-0.46 * * *$ & 0.08 & $-0.81 * * *$ & 0.09 \\
\hline Gender $($ female $=1)$ & $-0.49 * * *$ & 0.07 & $-0.33 * * *$ & 0.05 & $0.16^{*}$ & 0.08 \\
\hline Foreign language $(\mathrm{Yes}=1)$ & 0.13 & 0.12 & 0.16 & 0.09 & -0.04 & 0.09 \\
\hline Family SES & 0.01 & 0.05 & -0.01 & 0.04 & -0.02 & 0.05 \\
\hline Family wealth & -0.003 & 0.04 & -0.05 & 0.03 & 0.04 & 0.04 \\
\hline $\begin{array}{l}\text { Family cultural } \\
\text { possessions }\end{array}$ & $0.28 * * *$ & 0.05 & $0.26^{* * *}$ & 0.03 & 0.02 & 0.04 \\
\hline $\begin{array}{l}\text { Family educational } \\
\text { resources }\end{array}$ & 0.05 & 0.04 & $0.19 * * *$ & 0.02 & $0.14 * *$ & 0.04 \\
\hline Constant & $-0.81 * * *$ & 0.08 & $1.44 * * *$ & 0.05 & $2.25 * * *$ & 0.06 \\
\hline
\end{tabular}




\section{Conclusion and Discussion}

Derived from the motivation theory in psychology, science motivation is usually scaled continuously. By scaling it thus, we can differentiate students based on the score intervals to which their science motivation scores belong. This research provides another point of view from which to consider middle school students' science motivation through identifying different patterns of motivation development. By applying LCA, we generated and further investigated an individual-based three-class solution. Students in the Class 1 motivation group tend to feel passive while learning science but have a relatively high expectation that science will benefit their career prospects. They constitute about $26 \%$ of the whole sample. In contrast to Class 1, students falling in Class 2 reported high enjoyment while learning science but did not believe science would be important for their careers. This is the smallest group, covering about $13 \%$ of the whole sample. Students in these two groups have mixed feelings about learning science and its value. That is to say, students in Class 1 don't like science but see that it might be beneficial for a future job, while students in Class 2 like science at school but do not currently see a future working in that area. Finally, Class 3 has over two thirds of the entire sample, implying that middle school students have high agreement with the science motivation items in the PISA survey. This result provides two important insights. First of all, it justifies the three-class model. Rejecting a dichotomized split, as used in previous research, is consistent with the examination completed by MacCallum and his colleges (MacCallum et al., 2002), in which a median-divided partition is considered misleading in quantitative research (Pastor et al., 2007). Secondly, different from previous grouping methods that rely on the mean or total scores of students' science motivation, our results identify three distinctive groups based on the responses to each item. It shows that science motivation does not increase linearly from low levels to high levels among the groups. Although a group with high probabilities of enjoying both positive experiences and prospects can be found in the analysis, we also observed one group holding a pragmatic view toward learning science related to employment and another group that finds pure enjoyment from learning itself.

Determining potential national differences is one focus of this research. Our analysis first shows that, in general, Chinese students have higher mean scores for all science motivation indicators. The same tendency can be found in the MNLM results that compared to their American counterparts, Chinese students are more likely to be in the class with high mean values for both science enjoyment and external motivation. As an empirical research study, it also sheds a light on understanding different patterns of motivation across cultures. Previous research has investigated cultural effects on motivation, mainly from the perspective of learning environments derived from different learning ideologies (Li, 2005). For instance, Pomerantz and colleagues argued that due to a strong emphasis on academic achievement, Chinese teachers and parents provide more support to students and are more involved in their studies (Pomerantz et al., 2008). This may help students sustain their learning motivation after their early adolescence. School structures may also contribute to the differences. Compared to Chinese schools, which usually place great emphasis on academic success, alternative activities in American schools may attract students' interest more than learning activities. 
Important indicators that have been examined in previous research include gender and family environment, and these manifest significant impact in this research too. Our results reject the ambiguous effect of gender on science motivation in the literature review. Compared to males, females are more likely to have lower intrinsic motivation but higher instrumental motivation. It means that although girls tend to believe science is important to their future, they do not gain much enjoyment from learning and taking science-related courses. Consistent with prior research, girls are also less likely than boys to be in the group with both the highest intrinsic and instrumental motivation. For instance, after examining junior high students in Shanghai, Feng argued that boys have higher intrinsic motivation than girls (Feng, n.d.). A similar pattern can be found in college-level students, where among non-science majors, women tend to believe that science is related to their career more strongly than men do (Glynn et al., 2007); while men have higher scores in the self-efficacy section than women (Glynn et al., 2011).

Family influence is important in differentiating students' motivation patterns in this research to some degree after controlling for students' gender and nationality. Those who have more family cultural possessions are more likely to be in the high learning enjoyment and low future prospect group than the opposite. Having more family cultural possessions also helps students to reach the group with highest motivation scores in both intrinsic and instrumental motivation relative to the group with only high intrinsic motivation. Also, we found that having more family educational resources is also associated with being more likely to be in the group with highest enjoyment and future prospects about science than the other two groups. In contrast, either parent's highest educational attainment or family wealth play an important role in predicting students' motivation class. A similar conclusion can be found in many research studies showing that parents' education is not strongly associated with students' science motivation and attitude after controlling for students' demographic features and learning ability (Stake, 2006). It implies that for science motivation, relevant resources provided by the family are more worthwhile in increasing students' science motivation than simply owning more wealth or education.

Several limitations are important to consider and may open the door for future investigations in this area. On one hand, our data is limited by the sample cities selected in PISA 2015, since the Chinese case only covers four regions in the country. According to the Report of Chinese Education Index published by the Changjiang Education Research Institute, all four of those regions are in the upper quantile of all provinces and cities, meaning that they have very strong performance in educational investment, equity, legislation, transparency and other areas (Changjiang Education Research Institute, 2017). Therefore, it may reduce the research project's representation power to merely use the data collected in educationally developed regions in China. On the other hand, science motivation items in the PISA 2015 mainly reflect students' self-evaluation about the enjoyment and future prospects they have in learning science disciplines. It suggests that future research can take into account all categories in a science motivation model to create a more comprehensive picture of science motivation. 


\section{References}

Alderson, A. S., Junisbai, A., \& Heacock, I. (2007). Social status and cultural consumption in the United States. Poetics, 35(2-3), 191-212. https://doi.org/10.1016/j.poetic.2007.03.005

Baker, D., \& Leary, R. (2003). Letting Girls Speak Out about Science. Journal of Research in Science Teaching, 40.

Britner, S. L., \& Pajares, F. (2001). Self-efficacy beliefs, motivation, race, and gender in middle school science. Journal of Women and Minorities in Science and Engineering, 7(4). https://doi.org/10.1615/JWomenMinorScienEng.v7.i4.10

Bryan, R. R., Glynn, S. M., \& Kittleson, J. M. (2011). Motivation, achievement, and advanced placement intent of high school students learning science. Science Education, 95(6), 1049-1065. https://doi.org/10.1002/sce.20462

Catsambis, S. (1995). Gender, race, ethnicity, and science education in the middle grades. Journal of Research in Science Teaching, 32(3), 243-257. https://doi.org/10.1002/tea.3660320305

Celeux, G., \& Soromenho, G. (1996). An entropy criterion for assessing the number of clusters in a mixture model. Journal of Classification, 13(2), 195-212. https://doi.org/10.1007/BF01246098

Changjiang Education Research Institute. (2017). Report of Chinese Education Index. http://cjjy.com.cn/jiaoyuzhishu/

Chen, C., Lee, S., \& Stevenson, H. W. (1996). Academic achievement and motivation of Chinese students: A cross-national perspective. In Growing up the Chinese way: Chinese child and adolescent development (pp. 69-92).

Crisp, G., Nora, A., \& Taggart, A. (2009). Student characteristics, pre-college, college, and environmental factors as predictors of majoring in and earning a stem degree: An analysis of students attending a hispanic serving institution. American Educational Research Journal, 46(4), 924-942. https://doi.org/10.3102/0002831209349460

Debacker, T. K., \& Nelson, R. M. (2000). Motivation to learn science: Differences related to gender, class type, and ability. The Journal of Educational Research, 93(4), 245-254. https://doi.org/10.1080/00220670009598713

Dunn, K. M., Jordan, K., \& Croft, P. R. (2006). Characterizing the course of low back pain: A latent class analysis. American Journal of Epidemiology, 163(8), 754-761. https://doi.org/10.1093/aje/kwj100

Feng, D. (n.d.). Case study on test anxiety and learning motivation of junior middle schools' students. Research of Modern Basic Education, 15, 74-78.

Freeman, B., Marginson, S., \& Tytler, R. (2014). The Age of STEM: Educational policy and practice across the world in Science, Technology, Engineering and Mathematics. Routledge. 
Gao, L. (1998). Cultural context of school science teaching and learning in the People's Republic of China. Science Education, 82(1), 1-13. https://doi.org/10.1002/(SICI)1098-237X(199801)82:1<1::AID-SCE1>3.0.CO;2-L

Glynn, S. M., Brickman, P., Armstrong, N., \& Taasoobshirazi, G. (2011). Science motivation questionnaire II: Validation with science majors and nonscience majors. Journal of Research in Science Teaching, 48(10), 1159-1176. https://doi.org/10.1002/tea.20442

Glynn, S. M., \& Koballa, T. R. (2006). Motivation to learn in college science. In J. J. Mintzes \& W. H. Leonard (Eds.), Handbook of College Science Teaching (illustrated edition, pp. 25-32). National Science Teachers Association.

Glynn, S. M., Taasoobshirazi, G., \& Brickman, P. (2007). Nonscience majors learning science: A theoretical model of motivation. Journal of Research in Science Teaching, 44(8), 1088-1107. https://doi.org/10.1002/tea.20181

Glynn, S. M., Taasoobshirazi, G., \& Brickman, P. (2009). Science motivation questionnaire: Construct validation with nonscience majors. Journal of Research in Science Teaching, 46(2), 127-146. https://doi.org/10.1002/tea.20267

Goodman, L. A. (2002). Latent class analysis: The empirical study of latent types, latent variables and latent structures. Applied Latent Class Analysis. https://ci.nii.ac.jp/naid/10020819331/

Kass, R. E., \& Raftery, A. E. (1995). Bayes factors. Journal of the American Statistical Association, 90(430), 773-795. JSTOR. https://doi.org/10.2307/2291091

Kempa, R. F., \& Diaz, M. M. (1990). Motivational traits and preferences for different instructional modes in science. International Journal of Science Education, 12(2), 195-203. https://doi.org/10.1080/0950069900120208

Kleinginna, P. R., \& Kleinginna, A. M. (1981). A categorized list of motivation definitions, with a suggestion for a consensual definition. Motivation and Emotion, 5(3), 263-291. https://doi.org/10.1007/BF00993889

Klonsky, E. D., \& Olino, T. M. (2008). Identifying clinically distinct subgroups of self-injurers among young adults: A latent class analysis. Journal of Consulting and Clinical Psychology, 76(1), 22-27. https://doi.org/10.1037/0022-006X.76.1.22

Lewin, K. M. (1987). Science education in China: Transformation and change in the 1980s. Comparative Education Review, 31(3), 419-441. https://doi.org/10.1086/446699

Li, J. (2005). Mind or Virtue: Western and Chinese Beliefs About Learning. Current Directions in Psychological Science, 190-194. https://doi.org/10.1111/j.0963-7214.2005.00362.x

MacCallum, R. C., Zhang, S., Preacher, K. J., \& Rucker, D. D. (2002). On the practice of dichotomization of quantitative variables. Psychological Methods, 7(1), 19-40. https://doi.org/10.1037//1082-989X.7.1.19 
Maltese, A. V., \& Tai, R. H. (2011). Pipeline persistence: Examining the association of educational experiences with earned degrees in STEM among U.S. students. Science Education, 95(5), 877-907. https://doi.org/10.1002/sce.20441

Marsh, H. W., Abduljabbar, A. S., Abu-Hilal, M. M., Morin, A. J. S., Abdelfattah, F., Leung, K. C., Xu, M. K., Nagengast, B., \& Parker, P. (2013). Factorial, convergent, and discriminant validity of timss math and science motivation measures: A comparison of Arab and Anglo-Saxon countries. Journal of Educational Psychology, 105(1), 108-128. https://doi.org/10.1037/a0029907

McCutcheon, A. L. (1987). Latent class analysis. SAGE.

Muthén, B. (1979). A structural probit model with latent variables. Journal of the American Statistical Association, 74(368), 807-811. https://doi.org/10.1080/01621459.1979.10481034

Muthén, B., \& Christoffersson, A. (1981). Simultaneous factor analysis of dichotomous variables in several groups. Psychometrika, 46(4), 407-419. https://doi.org/10.1007/BF02293798

Muthén, B., \& Muthén, L. K. (2000). Integrating Person-Centered and Variable-Centered Analyses: Growth Mixture Modeling With Latent Trajectory Classes. Alcoholism: Clinical and Experimental Research, 24(6), 882-891. https://doi.org/10.1111/j.1530-0277.2000.tb02070.x

Muthén, B. O. (1989). Latent variable modeling in heterogeneous populations. Psychometrika, 54(4), 557-585. https://doi.org/10.1007/BF02296397

Pastor, D. A., Barron, K. E., Miller, B. J., \& Davis, S. L. (2007). A latent profile analysis of college students' achievement goal orientation. Contemporary Educational Psychology, 32(1), 8-47. https://doi.org/10.1016/j.cedpsych.2006.10.003

Perna, L., Lundy-Wagner, V., Drezner, N. D., Gasman, M., Yoon, S., Bose, E., \& Gary, S. (2009). The contribution of HBCUS to the preparation of african american women for stem careers: A case study. Research in Higher Education, 50(1), 1-23. https://doi.org/10.1007/s11162-008-9110-y

Pomerantz, E., Ng, F., \& Wang, Q. (2008). Culture, parenting, and motivation: The case of East Asia and the United States. In M. L. Maehr, S. A. Karabenick, \& T. C. Urdan (Eds.), Advances in motivation and achievement: Social psychological perspectives (pp. 209-240). Emerald Group Publishing.

Rayman, P., \& Brett, B. (1995). Women science majors: What makes a difference in persistence after graduation? The Journal of Higher Education, 66(4), 388-414. JSTOR. https://doi.org/10.2307/2943794

Simpkins, S. D., Davis-Kean, P. E., \& Eccles, J. S. (2006). Math and science motivation: A longitudinal examination of the links between choices and beliefs. Developmental Psychology, 42(1), 70-83. https://doi.org/10.1037/0012-1649.42.1.70 


\section{Macrothink}

Stake, J. E. (2006). The critical mediating role of social encouragement for science motivation and confidence among high school girls and boys1: Social encouragement and science attitudes. Journal of Applied Social Psychology, 36(4), 1017-1045. https://doi.org/10.1111/j.0021-9029.2006.00053.x

StataCorp. (2017). Stata Statistical Software: Release 15. StataCorp LP.

Steele, C. M. (1997). A threat in the air: How stereotypes shape intellectual identity and $\begin{array}{lll}\text { performance. } & \text { American } & \text { Psychologist, }\end{array}$ https://doi.org/10.1037/0003-066X.52.6.613

Tuan, H., Chin, C., \& Shieh, S. (2005). The development of a questionnaire to measure students' motivation towards science learning. International Journal of Science Education, 27(6), 639-654. https://doi.org/10.1080/0950069042000323737

Wang, W., Wang, J., Zhang, G., Lang, Y., \& Mayer, V. J. (1996). Science education in the People's Republic of China. Science Education, 80(2), 203-222. https://doi.org/10.1002/(SICI)1098-237X(199604)80:2<203::AID-SCE5>3.0.CO;2-K

Weinburgh, M. (1995). Gender differences in student attitudes toward science: A meta-analysis of the literature from 1970 to 1991. Journal of Research in Science Teaching, 32(4), 387-398. https://doi.org/10.1002/tea.3660320407

\section{Copyright Disclaimer}

Copyright reserved by the authors.

This article is an open-access article distributed under the terms and conditions of the Creative Commons Attribution license (http://creativecommons.org/licenses/by/4.0/). 